\title{
Overproduction of $\alpha$-glucosidase in Aspergillus niger transformed with the cloned gene agIA
}

\author{
Dong Gun Lee, ${ }^{\dagger}$ Ikuko Nishimura-Masuda, ${ }^{\dagger \dagger}$ Akira Nakamura, Makoto Hidaka, \\ Haruhiko Masaki, and Takeshi Uozumi* \\ Department of Biotechnology, Graduate School of Agricultural and Life Sciences, \\ The University of Tokyo, Bunkyo-ku, Tokyo113-8657, Japan \\ (Received February 13, 1998; Accepted May 13, 1998)
}

\begin{abstract}
We have transformed an industrial strain, Aspergillus niger GN-3, with the $\alpha$-glucosidase gene (agIA) from the same strain. Southern hybridization analysis revealed that transformants had multiple copies of the cloned DNA inserted into the host genome. An 11-fold improvement of enzyme production was achieved by transformation with a DNA fragment composed of $1.11 \mathrm{~kb}$ of the $5^{\prime}$ noncoding region, $3.12 \mathrm{~kb}$ of the coding region containing three introns, and $1.2 \mathrm{~kb}$ of the $3^{\prime}$ noncoding region. It was found that the $3^{\prime}$ noncoding region $(1.2 \mathrm{~kb})$ was preferable for maximum production of the enzyme in the transformant.
\end{abstract}

Key Words_aglA; Aspergillus niger; $\alpha$-glucosidase; overproduction; transformation

Genes of starch-degrading enzymes of Aspergillus species have been cloned and characterized, e.g., glucoamylase (Boel et al., 1984), $\alpha$-amylase (Tada et al., 1989) , and $\alpha$-glucosidase (Minetoki et al., 1995a, b; Nakamura et al., 1997). Among these enzymes, $\alpha$ glucosidase of Aspergillus niger is useful for the production of novel oligosaccharides by using its transglucosidase activity (Kurimoto et al., 1997; Nakano et al., 1995). In the previous paper (Nakamura et al., 1997), we cloned the $\alpha$-glucosidase gene $(\mathrm{ag} / A)$ of $A$. niger GN-3 and found that it had an open reading frame of 985 amino acids split with three introns. We introduced the gene into Aspergillus nidulans and observed the gene expression. But the activity of the expressed enzyme was less than a third of that in the original strain GN-3, probably because of the low productivity of enzymes in the host, $A$. nidulans FGSC A89. In the present work, we have transformed $A$. niger GN-3 with the agIA gene and attained 11-fold as much production of $\alpha$-glucosidase as the host strain,

\footnotetext{
* Address reprint requests to: Dr. Takeshi Uozumi, Department of Biotechnology, Graduate School of Agricultural and Life Sciences, The University of Tokyo, 1-1-1 Yayoi, Bunkyo-ku, Tokyo113-8657, Japan.

${ }^{\dagger}$ Present address: Peptide Engineering Research Unit, Korea Research Institute of Bioscience and Biotechnology, KIST, Taejon, 305-600, Korea.

${ }^{+\dagger}$ Present address: Research and Development Division, Kikkoman Corporation, 399 Noda, Noda 278-0037, Japan.
}

GN-3.

\section{Materials and Methods}

Microbial strains, plasmids, and media. A. niger GN-3, an industrial strain for glucoamylase production provided by Amano Pharmaceutical Co., Ltd. (Nagoya, Japan) was used as both the DNA donor (Nakamura et al., 1997) and the recipient. Escherichia coli JM109 and $E$. coli MV1184 were used for propagation of the pUC vectors and their derivatives. Plasmid pDH25, containing the hygromycin resistance gene (hph) of $E$. coli (Cullen et al., 1987) was kindly provided by Dr. D. J. Henner.

YPD medium was composed of $0.5 \%$ yeast extract, $1 \%$ peptone, and $2 \%$ glucose $(\mathrm{pH} 5.0)$. For preparation of protoplasts, it was used with supplementation of $0.5 \% \mathrm{KH}_{2} \mathrm{PO}_{4}$ and $0.05 \% \mathrm{MgSO}_{4} \cdot 7 \mathrm{H}_{2} \mathrm{O}$. For regeneration of protoplasts, $0.8 \mathrm{M} \mathrm{NaCl}$ and methionine $(5 \mu \mathrm{g} / \mathrm{ml})$ were added to the supplemented medium because the strain GN-3 was a methionine auxotroph. To test the effect of carbon source on the productivity of $\alpha$-glucosidase, Czapek-Dox medium (3\% glucose, $0.3 \% \quad \mathrm{NaNO}_{3}, \quad 0.1 \% \quad \mathrm{KH}_{2} \mathrm{PO}_{4}, \quad 0.2 \% \quad \mathrm{KCl}, 0.05 \%$ $\mathrm{MgSO}_{4} \cdot 7 \mathrm{H}_{2} \mathrm{O}$, pH 5.5-6.0) containing methionine $(5 \mu \mathrm{g} / \mathrm{ml})$ was used with substitutions of glucose with starch or maltose.

DNA manipulation. Total cellular DNA was prepared from $A$. niger transformants according to Cullen 
et al. (1987). The preparation of plasmids from E. coli and the construction of recombinant plasmids were done according to the standard method (Sambrook et al., 1989).

Transformation of $A$. niger. An introduction of the cloned $\alpha$-glucosidase gene into $A$. niger $\mathrm{GN}-3$ was performed essentially according to the procedure of Gomi et al. (1987). To prepare protoplasts, conidia of A. niger GN-3 were inoculated into YPD medium and cultured at $30^{\circ} \mathrm{C}$ for $30 \mathrm{~h}$. The mycelia were harvested by filtration through $3 \mathrm{G} 1$ glass filter and washed with distilled water. The harvested mycelia were resuspended in $10 \mathrm{ml}$ of phosphate buffer (pH 6.0) containing $5 \mathrm{mg} / \mathrm{ml}$ Novozym 234, $5 \mathrm{mg} / \mathrm{ml}$ cellulase R-10, and $0.8 \mathrm{M} \mathrm{NaCl}$. The suspension was incubated at $30^{\circ} \mathrm{C}$ with gentle agitation. After $3 \mathrm{~h}$, the digests were filtered through $3 \mathrm{G} 3$ glass filter, and protoplasts in the filtrate were gathered by centrifugation at $2,000 \mathrm{rpm}$ for $5 \mathrm{~min}$. The protoplasts were resuspended in the washing buffer $\left(0.8 \mathrm{M} \mathrm{NaCl}, 10 \mathrm{mM} \mathrm{CaCl}_{2}\right.$, and $50 \mathrm{~mm}$ Tris- $\mathrm{HCl}, \mathrm{pH}$ 7.5) and centrifuged again. The washing step was performed twice. The protoplasts were then suspended in the washing buffer at a concentration of about $2.5 \times 10^{8}$ per milliliter.

Cotransformation (Kelly and Hynes, 1985; Punt et al., 1987) of various recombinant plasmids and the hygromycin resistance plasmid $\mathrm{pDH} 25$ was used to select transformants. Thus approximately $5 \times 10^{7}$ protoplasts were transformed with a mixture of $20 \mu \mathrm{g}$ of recombinant plasmid containing the $\alpha$-glucosidase gene and $10 \mu \mathrm{g}$ of $\mathrm{pDH} 25$ in the presence of $8 \%(\mathrm{~W} / \mathrm{V})$ of PEG 4000 and $18 \mathrm{mM} \mathrm{CaCl}_{2}$; they were regenerated in soft agar overlays and selected on the YPD medium containing $0.8 \mathrm{M} \mathrm{NaCl}$ and hygromycin $\mathrm{B}(100 \mu \mathrm{g} / \mathrm{ml})$. On the selection plates, a few large colonies were observed with several small ones. Most of the small colonies showed stunted growth and seemed to be abortive transformants. The large colonies were regarded as putative transformants and subjected to further investigation with single colony isolation and assay of the $\alpha$-glucosidase activity.

Enzyme assay. To perform $\alpha$-glucosidase assay, each transformant strain was cultured at $30^{\circ} \mathrm{C}$ for 2 to 6 days in $10 \mathrm{ml}$ of liquid YPD medium containing $100 \mu \mathrm{g} / \mathrm{ml}$ hygromycin B. The cultures were centrifuged at $1,500 \mathrm{rpm}$ for $5 \mathrm{~min}$, and the supernatants were filtered through $0.45 \mu \mathrm{m}$ filter and concentrated to 0.05 volume by Centricon 30 (Amicon, Beverly, MA, U.S.A.) to get the crude enzyme solutions. The enzyme activity was determined by the method of Iwano et al. (1977) by using methyl- $\alpha$-glucoside as the substrate and measuring the amount of produced glucose by dinitrosalicylic acid method as mentioned previously (Nakamura et al., 1997). One unit (U) of the activity was defined as the production of $1 \mu \mathrm{mol}$ of glu- cose per minute.

For the determination of glucoamylase activity, reaction was carried out at $37^{\circ} \mathrm{C}$ for $30 \mathrm{~min}$ in $0.5 \mathrm{ml}$ of $0.05 \mathrm{M}$ sodium acetate buffer $(\mathrm{pH} 4.5)$ containing $1 \%$ starch and $0.05 \mathrm{ml}$ of the crude enzyme. The amount of produced glucose was assayed by a kit, Glucose CII Test (Wako Jun-yaku Kogyo, Ltd., Osaka, Japan), which uses glucose oxidase and mutarotase in combination. One unit $(U)$ of the activity was defined as the production of $1 \mu \mathrm{mol}$ of glucose per minute.

The protein concentration of the crude enzyme was determined by using a BIO-RAD protein assay kit (Hercules, CA, USA). And the productivity of the two enzymes in various transformants was expressed by the activity $(U)$ per milligram of protein in the crude enzyme.

\section{Results and Discussion}

\section{Construction of recombinant plasmids}

pGTI43 was constructed by insertion of the $4.3-\mathrm{kb}$ Sphl fragment (nucleotide no. 1-4300) containing the aglA gene (Nakamura et al., 1997) into pUC19. The fragment contained $1,140 \mathrm{bp}$ of the $5^{\prime}$ noncoding region, 3,124 bp of the coding region (including three introns), and $36 \mathrm{bp}$ of the $3^{\prime}$ noncoding region (Fig. 1). Another plasmid pGTI55, which was constructed by ligation of the 5.5-kb Bam HI-Sacl fragment between the $\mathrm{BamHI}$ and $\mathrm{Sacl}$ sites of pUC19, was $30 \mathrm{bp}$ shorter in the $5^{\prime}$ region compared with pGTI43, and it had an additional 1.2-kb Sphl-Sacl fragment in the 3' region. There was no typical polyadenylation signal (AATAAA) in the $701 \mathrm{bp}$ of the $3^{\prime}$ noncoding region extending down to the Pstl site at the nucleotide number 4965, sequenced so far (Nakamura et al., 1997). pGTI23 was constructed by ligation of 2.3-kb PvullEcoRI fragment (nucleotide no. 1279-3539) between Hincll and EcoRI sites of pUC19. It had a truncated $\alpha$-glucosidase gene lacking $138 \mathrm{bp}$ at the $5^{\prime}$ coding region and $725 \mathrm{bp}$ at the $3^{\prime}$ coding region.

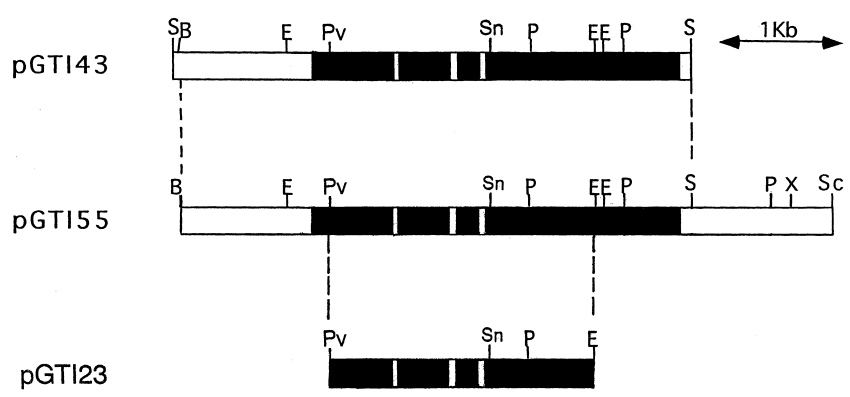

Fig. 1. The restriction maps of the inserted fragments of pGTI43, pGTI55, and pGTI23.

The black bar shows the amino acid coding region of the $\alpha$-glucosidase gene (aglA). S, Sphl; B, BamHI; E, EcoRI; Pv, Pvull; Sn, SnaBl; P, Pstl; Sc, Sacl; X, Xbal. 

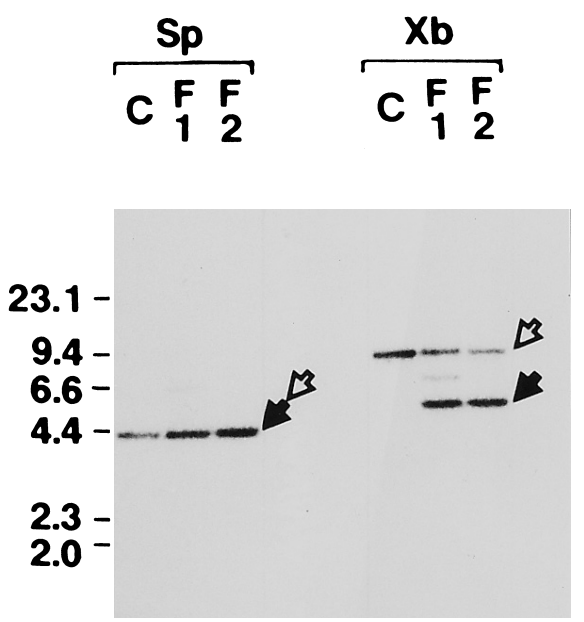

Fig. 2. Southern-blot analysis of the DNA from A. niger transformants.

Ten micrograms of the DNAs were digested with $S p h l(S p)$ or $X$ bal $(\mathrm{Xb})$ and loaded onto each lane, and the $2.6 \mathrm{~kb}$ EcoRl fragment corresponding to the main part of the $\alpha$-glucosidase gene (aglA) (Nakamura et al., 1997) was used as a probe. The transformants, F1 and F2, were obtained by transformation with pGTI55, whereas the control transformant, $\mathrm{C}$, was obtained with the vector pUC19. The numbers at the left show the position of the molecular standards ( $\lambda$-Hindlll digest) in $\mathrm{kb}$. The open arrow shows the aglA gene fragments derived from the original genome. The closed arrow shows the aglA gene fragments acquired by transformation.

\section{Transformation}

Cotransformation of $A$. niger GN-3 by using pDH25 as the marker was performed with the recombinant plasmids, pGTI55, pGTI43, pGTI23, and the vector pUC19, and 9, 8, 3, and 2 transformant colonies were obtained, respectively. They were transferred onto a YPD plate containing hygromycin B $(100 \mu \mathrm{g} / \mathrm{ml})$ and grown until full conidia formation. The conidia were suspended in $0.85 \% \mathrm{NaCl}$ and spread on the YPD plate with hygromycin $B$ to obtain single colonies.

The productivity of $\alpha$-glucosidase of 9 transformants from pGTI55 was 1- to 3.5 -fold compared with the control transformant with pUC19. Two of the representative transformants were named F1 and F2 (standing for full length). Eight transformants obtained from pGTI43 showed 1- to 3-fold productivity of the enzyme compared with the control transformant. Two were named S1 and S2 (standing for short in the $3^{\prime}$ noncoding region). Three transformants from pGTI23 showed 1 - to $1 / 3$-fold productivity of $\alpha$-glucosidase compared with the control transformant. Two were named T1 and T2 (standing for truncated). One transformant from pUC19 was named C (control).

Southern hybridization of the DNA of transformants $\mathrm{F} 1, \mathrm{~F} 2$, and $\mathrm{C}$ showed that the $\alpha$-glucosidase gene was amplified several-fold in transformants F1 and F2 (Fig. 2).

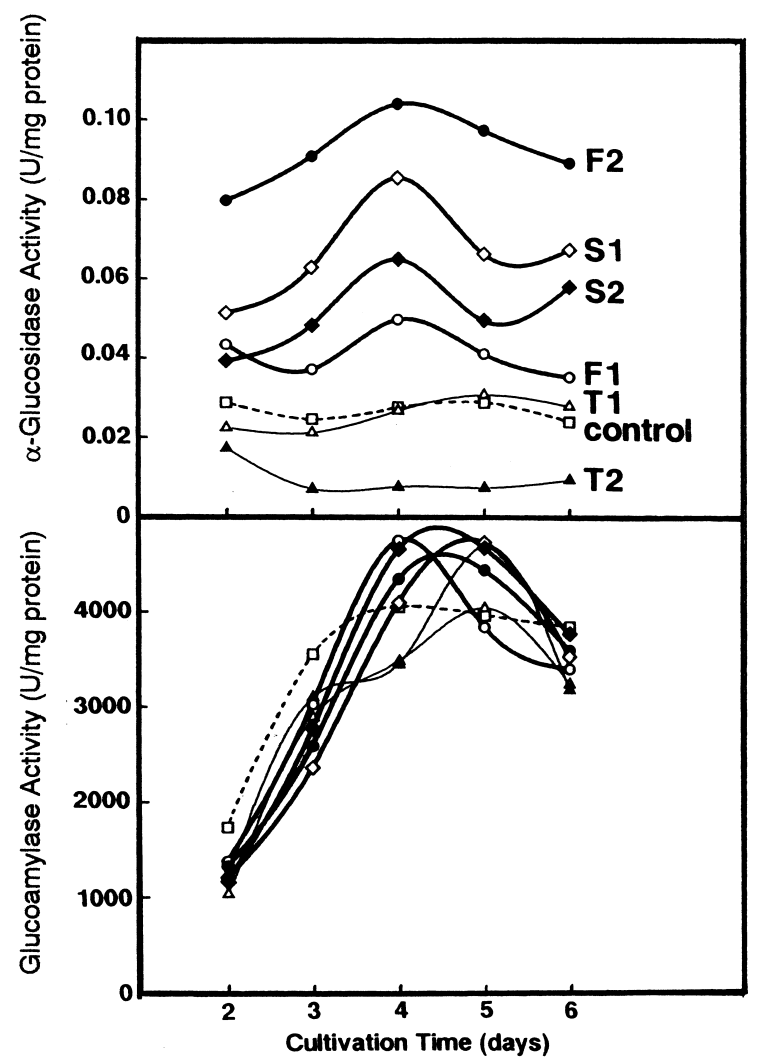

Fig. 3. Productivity of $\alpha$-glucosidase and glucoamylase of various transformants.

Conidia harvested from one fourth of a plate of culture were inoculated in $200 \mathrm{ml}$ of YPD medium containing hygromycin B $(100 \mu \mathrm{g} / \mathrm{ml})$ in $500-\mathrm{ml}$ conical flask with baffles and cultured at $30^{\circ} \mathrm{C}$ with shaking. Sampling was done daily during 2 to 6 days of culture.

\section{Productivity of $\alpha$-glucosidase of the transformants}

The time course of the $\alpha$-glucosidase produced extracellularly in the shaking culture was expressed by the specific activity of the crude enzyme (Fig. 3). In general, activity was highest at 4 days culture. The productivity of transformants $\mathrm{F} 1, \mathrm{~F} 2, \mathrm{~S} 1$ and S2 then was 1.8-, 3.7-, 3.0-, and 2.3-fold, respectively, compared with the control transformant $\mathrm{C}$. The improvement of productivity is presumably due to gene amplification, although the positional effect on gene expression depending on the locus where the gene is inserted may be combined.

One transformant with the truncated gene, T1, showed the same productivity as the control transformant with pUC19, whereas another one, T2, showed only a third of it. This result is reasonable because the homologous insertion of the truncated DNA into the $\alpha$ glucosidase gene should result in gene disruption, whereas its insertion onto a nonhomologous locus will not affect the original gene or the productivity of the enzyme. The reason why T2 productivity was not zero is not known. However, a possibility remains that the 
truncated enzyme, if produced, might have some activity because the degree of truncation is not sufficient.

As the control, the productivity of glucoamylase was also determined, and it was found to be essentially the same for all 7 transformants (Fig. 3), indicating that the general ability of extracellular enzyme production was not affected in these transformants.

\section{Purification of the transformants by repeated single colony isolation}

As mentioned above, fungal transformation with a single plasmid usually gives transformants with various productivity of the enzyme because the locus of incorporation and copy number of the incorporated gene are different among transformants. Furthermore, the purity of a transformant colony may be an important problem. Supposedly, the initial transformant protoplast may be a heterocaryon with a transformed nucleus and nontransformed nuclei. After regeneration and full growth on a plate, it will give rise to conidia with each single nucleus. But conidia with a transformed nucleus and conidia with a nontransformed nucleus may exist in a tightly connected chain of conidia on the conidiophore, and it may not be easy to isolate a single colony derived from a single conidium.

To attain the purity of the transformants, we performed the transformation of $A$. niger $\mathrm{GN}-3$ again with pGTI55 and pGTI43. This time the obtained transformant was thoroughly purified through two cycles of single colony isolation as follows. Each transformant was grown on a YPD plate to give conidia. The conidia from one plate were suspended in $10 \mathrm{ml}$ of $0.01 \%$ Tween-80, vortexed to separate conidia, and filtered through a $3 G 3$ glass filter. The filtered suspension was plated onto YPD plate containing hygromycin B $(100 \mu \mathrm{g} / \mathrm{ml})$ to obtain isolated single colonies.

By transformation with pGTI55, five transformant colonies (GTI55-A to E) were obtained. Conidia of these transformants were inoculated into $10 \mathrm{ml}$ of YPD medium and cultured at $30^{\circ} \mathrm{C}$ for 5 days with shaking. They showed the productivity of $\alpha$-glucosidase in the medium ranging from 22 to $74 \mathrm{mU} / \mathrm{mg}$ protein, compared with the activity $(20 \mathrm{mU} / \mathrm{mg})$ of the host $A$. niger GN-3 (Table 1, column A). Four transformants (GTI43A to D) were obtained from pGTI43, and their activity ranged from 28 to $41 \mathrm{mU} / \mathrm{mg}$.

Each transformant of the highest activity, i.e., GTI55-A and GTI43-A, were subjected to single colony isolation and gave colonies GTI55-A1 to A5 and GTI43-A1 to A4, respectively, which showed a variety of the enzyme production (Table 1, column B). Each colony of the highest activity, i.e., GTI55-A3 and GTI43-A4, were again subjected to single colony isolation and gave colonies GTI55-A3.1 to A3.4 and GTI43-A4.1 to A4.5, as shown in Table 1, column C.
Table 1. Productivity of $\alpha$-glucosidase in the original transformants and their successive single colony isolates.

\begin{tabular}{cccrcr}
$\begin{array}{c}\text { A. Original transformants } \\
(\mathrm{mU} / \mathrm{mg})\end{array}$ & \multicolumn{2}{c}{$\begin{array}{c}\text { B. First isolates } \\
(\mathrm{mU} / \mathrm{mg})\end{array}$} & $\begin{array}{c}\text { C. Second isolates } \\
(\mathrm{mU} / \mathrm{mg})\end{array}$ \\
\hline GTI55-A & 74 & GTI55-A1 & 29 & GTI55-A3.1 & 29 \\
GTI55-B & 22 & GTI55-A2 & 46 & GTI55-A3.2 & 75 \\
GTI55-C & 47 & GTI55-A3 & 101 & GTI55-A3.3 & 63 \\
GTI55-D & 23 & GTI55-A4 & 34 & GTI55-A3.4 & 240 \\
GTI55-E & 47 & GTI55-A5 & 12 & & \\
GTI43-A & 41 & GTI43-A1 & 28 & GTI43-A4.1 & 41 \\
GTI43-B & 28 & GTI43-A2 & 10 & GTI43-A4.2 & 19 \\
GTI43-C & 31 & GTI43-A3 & 19 & GTI43-A4.3 & 53 \\
GTI43-D & 37 & GTI43-A4 & 29 & GTI43-A4.4 & 20 \\
& & & & GTI43-A4.5 & 29 \\
GN-3 & 20 & GN-3 & 19 & GN-3 & 21 \\
& & & & C & 19 \\
\hline
\end{tabular}

GN-3 is the host strain without transformation. $C$ is a control transformant with pUC19. See text for the derivation of other transformants.

The highest activity $(240 \mathrm{mU} / \mathrm{mg})$ was attained by the purified colony GTI55-A3.4 from a transformant with pGTI55, which was 11 or 13 times as much as the host strain GN-3 $(21 \mathrm{mU} / \mathrm{mg})$ or the control transformant $(C)$ with pUC19 $(19 \mathrm{mU} / \mathrm{mg})$. On the other hand, the highest activity given by the purified transformant (GTI43-A4.3) from pGTI43 was $53 \mathrm{mU} / \mathrm{mg}$, which was 2.5 or 2.8 times as much as GN-3 or the control transformant $(\mathrm{C})$. The tendency that a structure containing a longer $3^{\prime}$ noncoding region of $\alpha$-glucosidase gene gives rise to transformants of higher productivity of the enzyme was also observed in the transformation of $A$. nidulans (Nakamura et al., 1997). It seems that a sufficient length of the $3^{\prime}$ region is important for maximum expression of the gene.

The variability of the enzyme productivity even in the final single colony isolates in Table 1, column C, shows the difficulty of strain purification and also suggests a possibility of the instability of the transformant, which should be examined in future cases of industrial use.

\section{Effect of carbon source on $\alpha$-glucosidase production}

Productions of many amylolytic enzymes are usually regulated by the carbon source in the medium. When the $\alpha$-glucosidase gene was introduced into $A$. nidulans (Nakamura et al., 1997), the transformant showed a high productivity of the enzyme ranging from 15 to $18 \mathrm{mU} / \mathrm{mg}$ protein in a medium using starch or maltose as the carbon source, whereas the productivity was reduced to 5 or $2 \mathrm{mU} / \mathrm{mg}$ in a medium containing only glucose or starch plus glucose, respectively, as the carbon source. We presumed that the effect was attributable to the presence of five sequences corresponding to $5^{\prime}-\mathrm{G} / \mathrm{CPyGGGG-3}$ ' in the 


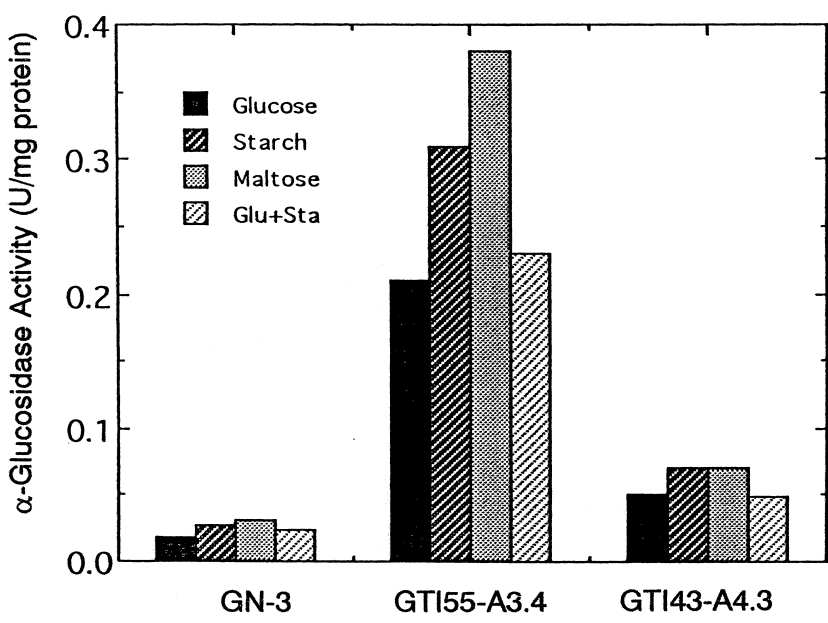

Fig. 4. Effect of carbon sources on the productivity of $\alpha$-glucosidase by $A$. niger $\mathrm{GN}-3$ and transformants.

A. niger GN-3 and the transformants, GTI55-A3.4, and GTI43A4.3, were cultured in $10 \mathrm{ml}$ of Czapek-Dox medium containing glucose, starch, maltose, or glucose plus starch as the carbon source, each at a concentration of $3 \%$, at $30^{\circ} \mathrm{C}$ for 5 days. The activity of the crude enzyme in the culture broth was measured and expressed as U per mg protein.

promoter region, which had been reported to work as the binding site of the carbon catabolite repressor CreA protein in A. nidulans (Kulmburg et al., 1993).

We checked whether such an effect of carbon source on the productivity of $\alpha$-glucosidase is observed also in $A$. niger $\mathrm{GN}-3$ and the transformants (Fig. 4). The result shows that productivity is generally high in a medium with starch or maltose and low in a medium containing glucose, but the effects of induction by starch or maltose and repression by glucose were not so conspicuous as in the case of $A$. nidulans. Because GN-3 is an industrial strain for the production of glucoamylase, some part of the mechanism for catabolite repression by glucose seems to have been lost during repeated mutagenesis for improvement of the productivity. Presumably the mutation should have occurred on the gene of the trans factor, i.e., on the repressor and not on the cis element, because the regulation is effectively functional in $A$. nidulans transformant with the $\alpha$-glucosidase gene (Nakamura et al., 1997).

The transformant strain A. niger GTI55-A3.4 should be advantageous for the industrial production of $\alpha$-glucosidase, which is currently supplied as a by-product of glucoamylase production.

We thank Amano Pharmaceutical Co. for supplying the strain $A$. niger GN-3. This work was performed at the facilities of Biotechnol- ogy Research Center, The University of Tokyo.

\section{References}

Boel, E., Hansen, M. T., Hjort, I., Hoeegh, I., and Fill, N. P. (1984) Two different types of intervening sequences in the glucoamylase gene from Aspergillus niger. EMBO J., 3, 1581-1585.

Cullen, D., Leong, S. A., Wilson, L. J., and Henner, D. J. (1987) Transformation of Aspergillus nidulans with hygromycin-resistance gene, hph. Gene, 57, 21-26.

Gomi, K., limura, Y., and Hara, S. (1987) Integrative transformation of Aspergillus oryzae with a plasmid containing the Aspergillus nidulans argB gene. Agric. Biol. Chem., 51, 2549-2555.

Iwano, K., Sato, M., Shibata, K., Mitsunaga, K., and Nunokawa, Y. (1977) Determination of transglucosidase activity in the presence of contaminating $\alpha$-amylase and glucoamylase. J. Brew. Soc. Jpn., 72, 459-462 (in Japanese).

Kelly, J. M. and Hynes, M. J. (1985) Transformation of Aspergillus niger by the amdS gene of Aspergillus nidulans. EMBO J., 4, 475-479.

Kulmburg, P., Mathieu, M., Dowzer, C., Kelly, J., and Felenbok, B. (1993) Specific binding sites in the alcR and alcA promoters of the ethanol regulon for the CREA repressor mediating carbon catabolite repression in Aspergillus nidulans. Mol. Microbiol., 7, 847-857.

Kurimoto, M., Nishimoto, T., Nakada, T., Chaen, H., Fukuda, S., and Tsujisaka, Y. (1997) Synthesis by an $\alpha$-glucosidase of glycosyltrehaloses with an isomaltosyl residue. Biosci. Biotech. Biochem., 61, 699-703.

Minetoki, T., Gomi, K., Kitamoto, K., Kumagai, C., and Tamura, G. (1995a) Nucleotide sequence and expression of $\alpha$-glucosidaseencoding gene (agdA) from Aspergillus oryzae. Biosci. Biotech. Biochem., 59, 1516-1521.

Minetoki, T., Gomi, K., Kitamoto, K., Kumagai, C., and Tamura, G. (1995b) Characteristic expression of three amylase-encoding genes, agdA, amyB, and glaA in Aspergillus oryzae transformants containing multiple copies of the agdA gene. Biosci. Biotech. Biochem., 59, 2251-2254.

Nakamura, A., Nishimura, I., Yokoyama, A., Lee, D. G., Hidaka, M., Masaki, H., Kimura, A., Chiba, S., and Uozumi, T. (1997) Cloning and sequencing of an $\alpha$-glucosidase gene from $A s$ pergillus niger and its expression in A. nidulans. J. Biotechnol., 53, 75-84.

Nakano, H., Hamayasu, K., Fujita, K., Hara, K., Ohi, M., Yoshizumi, H., and Kitahata, S. (1995) Synthesis of 2-deoxy-glucooligosaccharides through condensation of 2-deoxy-D-glucose by glucoamylase and $\alpha$-glucosidase. Biosci. Biotech. Biochem., 59 , 1732-1736.

Punt, P. J., Oliver, R. P., Dingemanse, M. A., Pouwels, P. H., and van den Hondel, C. A. M. J. J. (1987) Transformation of Aspergillus based on the hygromycin $B$ resistance marker from Escherichia coli. Gene, 56, 117-124.

Sambrook, J., Fritsch, E. F., and Maniatis, T. (1989) Molecular Cloning, 2nd ed., Cold Spring Harbor Laboratory Press, New York.

Tada, S., limura, Y., Gomi, K., Takahashi, K., Hara, S., and Yoshizawa, K. (1989) Cloning and nucleotide sequence of the genomic Taka-amylase A gene of Aspergillus oryzae. Agric. Biol. Chem., 53, 593-599. 